\title{
Cryotherapy for trichiasis in ocular cicatricial pemphigoid
}

\author{
Mark J Elder, Wolfgang Bernauer
}

\begin{abstract}
Trichiasis is a common and potentially sight threatening complication of ocular cicatricial pemphigoid and is usually secondary to cicatricial entropion. This study aimed to assess the success and complications of eyelid cryotherapy for trichiasis in a group of patients with long term follow up. The case records of all patients with ocular cicatricial pemphigoid that attended the external disease clinic at Moorfields Eye Hospital from 1980 to 1992 were reviewed. Each eyelid was divided into three horizontal zones. Cryotherapy was delivered with an Amoilette cryoprobe for approximately 30 seconds. Failure of the cryotherapy was defined as a regrowth of the eyelashes within the treated zone that either required epilation for symptom control or caused keratopathy. Ninety two lid zones were treated, involving 25 lids of 12 patients. The cumulative chance of success decreased rapidly to $\mathbf{4 0} \%$ over the first year. Thereafter, the chance of success declined slowly to $34 \%$ at 4 years. Complications included lid notching $(n=2)$, tarsal atrophy $(n=1)$, altered lid contour $(\mathbf{n}=1)$, and temporarily raised intraocular pressure $(n=1)$. All patients had quiescent disease at the time of the cryotherapy and no patients showed increased conjunctival disease activity after treatment. Six patients were taking systemic immunosuppression medication. When ocular cicatricial pemphigoid is quiescent, lid cryotherapy has an acceptable complication rate. The major reason for recurrence of the trichiasis was attributed to inadequate follicle freezing.

(Br F Ophthalmol 1994; 78: 769-771)
\end{abstract}

Trichiasis is a common and potentially sight threatening complication of ocular cicatricial pemphigoid (OCP). It is usually secondary to cicatricial entropion and may involve either the upper or lower lid. It may cause punctate epitheliopathy or corneal abrasions and may contribute to infectious keratitis which occurs in $10 \%$ of cases of OCP. ${ }^{12}$ Secondary mechanical irritation may provoke additional inflammation and this may influence conjunctival fibrosis. It may also evoke squamous metaplasia and increase ocular surface symptoms. The aims of this study were to evaluate the complications and success rate of cryotherapy in trichiasis associated with OCP. All the patients who underwent cryotherapy for trichiasis associated with OCP between 1980 and 1992 were included in this retrospective analysis.

Patients and methods

A review of the Moorfields Eye Hospital database for OCP was undertaken. Fifty two patients with OCP attending the external diseases clinic between 1980 and 1992 were identified. Twelve patients had cryotherapy for trichiasis during this period; 11 patients had biopsy proved OCP; one patient was biopsy negative but the patient had characteristic subepithelial fibrosis and progressive conjunctival cicatrisation. The mean age was 73.5 (range 59-82) years. Ten patients were men. Six patients were on systemic immunosuppression at the time of cryotherapy; four on dapsone, one on azathioprine, and one on prednisolone (for Crohn's disease). All patients but one had chronic cicatrisation without conjunctival hyperaemia. One patient had subacute disease with mild conjunctival hyperaemia.

Because all or part of a lid may be affected by trichiasis, the lids were divided horizontally into thirds and these were considered as isolated zones. Failure was defined as a recurrence of the lashes sufficient to either require epilation for control of symptoms or the development of lash related keratopathy. Particular regard was given to any complications such as inflammatory activity and/or progressive cicatrisation.

The cryotherapy was delivered using an Amoilette cryoprobe (Keeler Instruments, UK) applied to the posterior lid surface and of such duration as to freeze completely the area of the trichiatic follicles. This cryoprobe is $2 \mathrm{~mm}$ in diameter and has a rounded end. The effect of the cryotherapy was judged by ensuring complete 'whitening' of the trichiatic area, and the freezing time ranged from 30 to 60 seconds. For each treatment, two applications of cryotherapy were delivered, allowing complete, slow thawing between each. No thermocouple was used.

\section{Results}

This involved 92 treatments, 25 eyelids, and 12 patients. The upper lid had trichiasis in $56 \%$ (14/25), with $13 / 14$ having medial trichiasis, $8 / 14$ having lateral trichiasis, and 5/14 having trichiasis involving the middle third. The lower lid was affected in $44 \%$ (11/25). Medial trichiasis occurred in $7 / 11$, lateral trichiasis in $7 / 11$, and middle third trichiasis in 8/11 affected lids.

The classification systems for OCP refer only to an eye rather than each eyelid. Using Mondino's classification, ${ }^{3-5} 3 / 16$ eyes with trichiasis were stage $2,8 / 16$ were stage 3 , and $5 / 16$ were stage 4 . Using Foster's classification, ${ }^{6} .4 / 16$ eyes with trichiasis were stage $2,9 / 16$ were stage 3 , and $3 / 16$ were stage 4 .

Of the complications, two lids developed notching, one lid developed asymptomatic tarsal atrophy, and one lid developed an altered lid contour. One patient, who had pre-existing glaucoma and a moderately shortened fornix, 
Table 1 Cumulative chance of success of cryotherapy in ocular cicatricial pemphigoid

\begin{tabular}{|c|c|c|c|c|c|c|}
\hline $\begin{array}{l}\text { Post-treatment } \\
\text { interval (months) }\end{array}$ & $\begin{array}{l}\text { Number of zones } \\
\text { at interval } \\
\text { beginning }\end{array}$ & $\begin{array}{l}\text { Number of } \\
\text { zones withdrawn } \\
\text { in the interval }\end{array}$ & $\begin{array}{l}\text { Number of } \\
\text { zones at risk }\end{array}$ & $\begin{array}{l}\text { Number of } \\
\text { failures during } \\
\text { the interval }\end{array}$ & $\begin{array}{l}\text { Chance of } \\
\text { success }\end{array}$ & $\begin{array}{l}\text { Cumulative } \\
\text { chance of } \\
\text { success }\end{array}$ \\
\hline $\begin{array}{c}0-3 \\
4-6 \\
7-9 \\
10-12 \\
13-15 \\
16-18 \\
19-21 \\
22-24 \\
25-27 \\
28-30 \\
31-33 \\
34-36 \\
37-39 \\
40-42 \\
43-45 \\
46-48\end{array}$ & $\begin{array}{l}92 \\
74 \\
52 \\
45 \\
32 \\
30 \\
29 \\
28 \\
27 \\
26 \\
25 \\
25 \\
24 \\
23 \\
21 \\
20\end{array}$ & $\begin{array}{l}0 \\
1 \\
3 \\
2 \\
2 \\
1 \\
0 \\
1 \\
0 \\
1 \\
0 \\
0 \\
0 \\
2 \\
1 \\
3\end{array}$ & $\begin{array}{l}92 \\
73 \cdot 5 \\
50 \cdot 5 \\
44 \\
31 \\
29 \cdot 5 \\
29 \\
27 \cdot 5 \\
27 \\
25 \cdot 5 \\
25 \\
25 \\
24 \\
22 \\
20 \cdot 5 \\
18 \cdot 5\end{array}$ & $\begin{array}{r}18 \\
21 \\
4 \\
11 \\
0 \\
0 \\
1 \\
0 \\
1 \\
0 \\
0 \\
1 \\
1 \\
0 \\
0 \\
0\end{array}$ & $\begin{array}{l}0.8043 \\
0.7143 \\
0.9201 \\
0.7500 \\
1.0 \\
1.0 \\
0.9695 \\
1.0 \\
0.9630 \\
1.0 \\
1.0 \\
0.9600 \\
0.9583 \\
1.0 \\
1.0 \\
1.0\end{array}$ & $\begin{array}{l}0.8043 \\
0.5745 \\
0.5290 \\
0.3968 \\
0.3968 \\
0.3968 \\
0.3831 \\
0.3831 \\
0.3689 \\
0.3689 \\
0.3689 \\
0.3541 \\
0.3393 \\
0.3393 \\
0.3393 \\
0.3393\end{array}$ \\
\hline
\end{tabular}

had a rise of intraocular pressure (IOP) from $26 \mathrm{~mm} \mathrm{Hg}$ preoperatively to $43 \mathrm{~mm} \mathrm{Hg}$ the day after cryotherapy. This fell to $25 \mathrm{~mm} \mathrm{Hg}$ by day 3 on no treatment. Most patients developed significant lid oedema but no patient developed new symblepharon, extended existing symblephara, or otherwise activated their disease. One patient had three unsuccessful treatments only to have his trichiasis resolved after starting dapsone. This was associated with a decrease in the conjunctival inflammation and a mild but significant improvement in the cicatricial entropion.

The results of the success of the cryotherapy have been analysed using an actuarial method (Table 1) and are presented as a life table ${ }^{7}$ (see Fig 1). There is a rapid recurrence of the trichiatic lashes that persists up to approximately 12 months. Thereafter, the cumulative chance of success remains the same up to at least 4 years.

\section{Discussion}

The pathological reaction to cryotherapy depends on the temperature to which the tissues are subjected. In rabbits, at $-15^{\circ} \mathrm{C}$, there is complete retention of the lash follicles but significant, permanent depigmentation of the melanocytes. At $-30^{\circ} \mathrm{C}$, the follicles and the meibomian glands are replaced by a dermal scar. ${ }^{8}$ Effective cryotherapy for trichiasis will always be accompanied by a hypopigmented epidermis because the melanocytes are more sensitive to cryotherapy than lash follicles..$^{9}$ This is very important for dark skinned patients. However, cosmetically this may be reduced by splitting the eyelid and selectively treating the lash follicles or by only treating the lid margin and posterior lid surface. ${ }^{10}$ In humans, clinical studies suggest that $-20^{\circ} \mathrm{C}$ is satisfactory for lash ablation. ${ }^{11}$

Cryotherapy achieves a long term success rate of $70-90 \%$ in non-cicatricial lid disease, ${ }^{11-13}$ how-

Figure 1 Cummulative chance of success of cryotherapy for trichiasis.

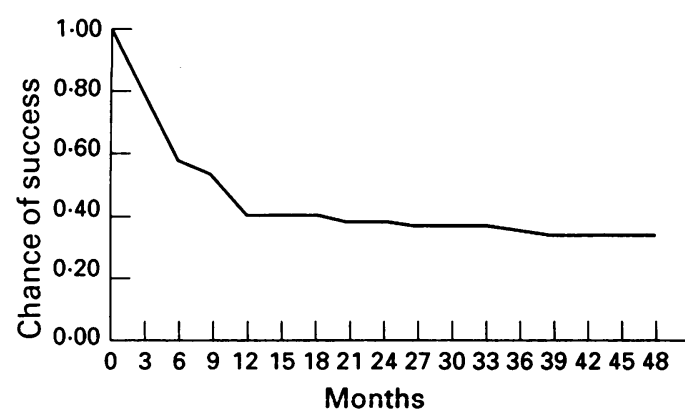

ever, complications occur in up to $26 \% .^{13}$ These include severe short term lid oedema, lid depigmentation, destruction of meibomian glands, lid notching, and induction of further trichiasis (in 9\%). Marked progression of symblepharon and conjunctival scarring was noted in $77 \%$ of patients with OCP in the absence of immunosuppression. ${ }^{13}$ The 12 month success rate of cryotherapy in this study is $40 \%$, with many of the failures occurring at 3-6 months. This compares poorly with the $91 \%$ success found in noncicatricial causes of trichiasis. ${ }^{11}$ In cicatricial trichiasis, Collin et $a l^{12}$ had success of $49 \%$ (20/41) with follow up of at least 6 months, while Foster' claims a recurrence rate of 'approximately 10\%'. In trichiasis due to trachoma (which shares many features with OCP), cryotherapy was successful in $27-56 \%$. This is based on two studies that had assessed success with a Kaplan-Meier analysis over long periods. ${ }^{14} 15$ Each clinical study used a different cryoprobe. ${ }^{11-15}$

In this series, there were minimal complications from the cryotherapy. In particular, there is no evidence for disease progression after the cryotherapy. This lends credence to the opinion that, in OCP, the least complications occur in eyes without conjunctival inflammation. ${ }^{1416}$ This meant 'white eyes' in this study. The rise in IOP in one case was associated with conjunctival chemosis. The IOP rise may be explained by an increase in episcleral venous pressure which occurs as a result of the inflammatory dilatation of the precapillary arteriole sphincter. This allows the capillary and venous pressures to rise. Because $26 \%$ of patients with OCP have raised IOP at some stage of their disease, ${ }^{21}$ it would be prudent to monitor this in at risk patients.

Trichiasis occurred in stages 2-4 of both Mondino's and Foster's staging systems with almost equal occurrence between the different stages. Mondino's classification ${ }^{3-5}$ uses lower lid fornix depth as the sole criterion for staging - for example, stage 3 has a loss of depth of $50-75 \%$. Foster's staging ${ }^{6}$ relies on the presence of specific clinical signs. For example, stage 2 is fornix shortening of any degree, stage 3 is the presence of any symblepharon, and stage 4 is a frozen globe. Trichiasis per se seems poorly related to fornix depth or to the presence of symblepharon.

There was a marked difference in the prevalence of the location of trichiasis requiring cryotherapy in the upper lid. Trichiasis occurred 
in the medial lid in $93 \%$, in the lateral lid in $57 \%$, and in the middle third of the lid in $36 \%$. There was no such difference in the lower lid. Wright ${ }^{18}$ has observed that medial cicatrisation, with flattening of the canthal structures, occurs early in OCP. Therefore, if the trichiasis is due to entropion, then the medial trichiasis may be due to increased fibrosis in this area. However, if this is the sole explanation, then an increased prevalence of medial lower lid trichiasis would be expected. This was not observed. An alternative explanation is that the medial lid is less able to withstand the cicatricial posterior lamellar shortening because of less anatomical resilience to entropion and a naturally shallow medial fornix.

One explanation of the relative lack of success of cryotherapy in this series is that the base of the follicles did not achieve an adequately low temperature. This may have been because of an insulating effect of the scar tissue. Eyelash follicles are located just anterior to the tarsal plate and at a depth of approximately $2.5 \mathrm{~mm}$ from the lid margin. ${ }^{19}$ The only absolute method to ensure that there has been adequate freezing is to use a thermocouple at the level of the follicles. Clinically, various authors have often relied on a specific duration of freezing based on previous correlations with a thermocouple. However, this depends markedly on the type of probe used. For example, for an eyelid to reach $-20^{\circ} \mathrm{C}$ requires 45 seconds with the Cryomedics MT650 probe, 30 seconds with the Amoilette cryoprobe, and 25 seconds with the Collin cryoprobe. ${ }^{11-13}$ The other clinical method is to apply the cryotherapy until there has been adequate 'whitening' of the affected area. While this does compensate for individual variation, it relies on the assumption that the follicles have reached $-20^{\circ} \mathrm{C}$ because the skin has turned white. Neither method is entirely satisfactory. The laboratory evidence suggests that there is $100 \%$ destruction of lash follicles if they are frozen to $-30^{\circ} \mathrm{C}$ in two cycles. ${ }^{8}$ If this is correct, then the clinical failure is solely due to inadequate freezing of the follicles.

All of the current modalities of management of trichiasis have some shortcomings. Mechanical epilation, while straightforward, provides only temporary relief because regrowth occurs in 4-6 weeks. ${ }^{2021}$ Electrolysis is technically difficult, time consuming, and may result in significant scar formation. ${ }^{8}$ Long term cure occurs in $30-50 \% .{ }^{82022}$ Surgical techniques aim to correct the trichiasis by correcting the entropion, but in
OCP marked scarring results if there is no systemic control of the pemphigoid. ${ }^{1+1623}$ This may be avoided by using an external approach and avoiding surgery to the conjunctiva. ${ }^{24}$ Cryotherapy can treat large areas of lashes with minimal complications. The success rate in this study is similar to other techniques and may be improved if adequate follicle freezing is ensured.

The authors are grateful to Mr J K G Dart FRCS and Mr P Wright FRCS for allowing their patients to be described and $\mathrm{Mr} \mathrm{J} R \mathrm{O}$ Collin FRCS for his helpful advice.

The authors have no proprietary interest in the development or marketing of any equipment mentioned in this paper.

1 Foster CS. Cicatricial pemphigoid. Trans Am Ophthalmol Soc 1986; 84: 527-663.

2 Ormerod LD, Fong LP, Foster CS. Corneal infection in mucosal scarring disorders and Sjogren's syndrome. Am F Ophthalmol 1988; 105: 512-8.

3 Mondino BJ, Ross AN, Rabin BS, Brown SI. Autoimmune phenomena in ocular cicatricial pemphigoid. Am $\mathcal{F}$ Ophthal mol 1977; 83: 443-50.

4 Mondino BJ, Brown SI. Ocular cicatricial pemphigoid. Ophthalmology 1981; 88: 95-100.

5 Mondino BJ, Brown SI. Immunosuppressive therapy in ocular cicatricial pemphigoid. Am $\mathcal{F}$ Ophthalmol 1983; 96: 453-9.

6 Foster CS, Wilson LA, Ekins MB. Immunosuppressive therapy for progressive ocular cicatricial pemphigoid. Ophthalmology 1982; 89: 340-53.

$7 \mathrm{Kahn} \mathrm{HA,} \mathrm{Sempos} \mathrm{CT.} \mathrm{Statistical} \mathrm{methods} \mathrm{in} \mathrm{epidemiology.}$ Monographs in epidemiology and biostatistics. Vol 12. Oxford: Oxford University Press, 1989: 168-98.

8 Sullivan JH, Beard C, Bullock TD. Cryosurgery for treatment of trichiasis. Am f Ophthalmol 1976; 82: 117-21.

9 Soll DB, Harrison SE. Basic concepts and an overview of cryosurgery in ophthalmic plastic surgery. Ophthalmic Surg 1979; 10: 31-6.

10 Peart DA, Hill JC. Cryotherapy for trichiasis in black patients. Br f Ophthalmol 1986; 70: 712-4.

11 Johnson RJC, Collin JRO. Treatment of trichiasis with a lid cryoprobe. Br $\mathcal{F}$ Ophthalmol 1985; 69: 267-70.

12 Collin JRO, Coster DJ, Sullivan JH. Cryosurgery for trichiasis. Trans Ophthalmol Soc UK 1978; 98: 81-3.

13 Wood JR, Anderson RL. Complications of cryosurgery. Arch Ophthalmol 1981; 99: 460-3.

4 Reacher MH, Munoz B, Alghassany A, Daar AS, Elbualy M, Taylor HR. A controlled trial of surgery for trachomatous trichiasis of the upper lid. Arch Ophthalmol 1992; 110: 667-74.

15 Rice CD, Kersten RC, Al-Hazzaa S. Cryotherapy for trichiasis in trachoma. Arch Ophthalmol 1989; 107: 1180-2.

16 Mondino BJ, Brown SI, Lempert S, Jenkins MS. The acute manifestations of ocular cicatricial pemphigoid: diagnosis manifestations of ocular cicatricial pemphigoid

17 Tauber J, Melamed S, Foster CS. Glaucoma in patients with ocular cicatricial pemphigoid. Ophthalmology 1988; 96: 33-7.

18 Wright P. Enigma of cicatrising conjunctivitis. Trans Ophthal mol Soc UK 1986; 99: 141-4.

19 Duke-Elder S, Wybar KC. Anatomy of the eye. In: System of ophthalmology. Vol 2. St Louis: C V Mosby, 1961: 526.

20 Hartzler J, Nelder KH, Forster L. X-ray epilation for the treatment of trichiasis. Arch Dermatol 1984; 120: 620-4.

21 Bartley GB, Bullock JD, Olsen TG, Lutz PD. An experimental study to compare methods of eyelash ablation. Ophthalmolstudy to compare meth

22 Hecht SD. Cryotherapy of trichiasis with the use of the retinal cryoprobe. Ann Ophthalmol 1977; 9: 1501-3.

23 Mondino BJ, Brown SI, Rabin BS. Auto immune phenomenon of the external eye. Trans Am Acad Ophthalmol 1978; 85: 801 .

24 Rosser PM, Collin JRO. Retractor plication for lower lid entropion in ocular cicatricial pemphigoid. Aust $N Z \mathcal{F}$ Ophthalmol 1993; 21: 93-7. 